\title{
Urban Structure and Commuting in Australian Cities
}

\begin{abstract}
Studies looking at the relationship between urban form and travel behaviour have generally considered spatial information on coarse metropolitan or local government area scales. We analyse ABS Census data at the Collection District level for the metropolitan areas of the mainland Australian state capital cities, and at various spatial scales for an in-depth analysis of commuting in Sydney. The analyses suggest that the relationship between travel behaviour and urban form is complex, and that simple analyses of density alone are likely to overstate the effect of both metropolitan and neighbourhoodscale population density on mode choice, but that these variables serve as useful proxies for more complex measures of urban structure.
\end{abstract}

\section{Introduction}

There has been much interest by urban researchers in a variety of disciplines on the relationship between urban form and travel behaviour. The quantity of research in this area is large enough to support large bodies of work investigating (and often advocating) plans and policies to influence urban travel behaviour. For example, research indicating that higher population density, mixed land use, and transit provision result in significant shifts in travel behaviour has been the ammunition for those arguing for urban planning policies that favour higher-density development around public transport nodes (Cervero and Kockelman, 1997; Newman and Kenworthy, 1999). The motivation for such urban compaction is often environmental, although social, health, economic and aesthetic concerns are also cited (Newman and Kenworthy, 1989; Frumkin et al., 2004). Such policies, however, have not had unequivocal support, either in the research community (Troy, 1996; Levinson and Kumar, 1997; Holloway and Bunker, 2005), or amongst the general urban citizenry.

The principal aim of this article is not to advocate for or against particular planning policies, as there is an extensive literature on this already ${ }^{1}$. Instead, we will give a brief overview pointing to some of the major relevant publications on both sides, and then proceed with our more descriptive task - conducting an analysis of how spatial structure affects journey-to-work travel behaviour in contemporary Australian cities. We take a spatially disaggregated approach, but without adopting anything as sophisticated as the discrete choice model backed random utility framework typical in modern transport microsimulation, as such an approach would require extensive data collection and model calibration that would preclude us covering all mainland state capitals. Despite the simpler nature of our approach, we believe the breadth and spatial resolution of our coverage provides useful insights into how inter

\footnotetext{
${ }^{1}$ The nature of the data we analyse, however, makes some general policy related remarks inevitable.
} 
and intra city variations in spatial structure are associated with journey-to-work mode choice. Doing such an analysis for Australian cities, with broadly similar economic and cultural features, invites the possibility of inference not possible in international groupings due to the significant economic, political, and cultural differences inherent in comparisons of international cities.

\section{Review}

Most inter-city studies into the effect of urban density have used metropolitan population density, partly because this is a comparatively easy measurement to collect - an important consideration in inter-city comparisons. Intra-city research is more likely to use complex land-use measures, such as land-use mix (Cervero, 1996), jobs-housing balance (Cervero and Duncan, 2006), and regional (Rodriguez et al., 2006), or even U.S. Census Tract population density (Golob and Brownstone, 2005). Regarding the effect of density, the intra-city research is somewhat mixed, with some studies finding minimal (or no) effects of density after controlling for demographic effects (Crane and Crepeau, 1998), while others find significant effects (Geurs et al., 2006). Results from inter-city comparisons are also mixed, although the larger studies (such as Kenworthy and Laube (1999); Badoe and Miller (2000); Ewing et al. (2001); Bento et al. (2003); Baum-Snow and Kahn (2005)) generally support the notion that some measure of population distribution is important, although even here there are exceptions, such as the review by Boarnet and Crane (2001). It is generally understood that many other factors besides macro-scale density have an effect on travel behaviour in cities. Among them are total city population, geographic constraints on city shape and transport infrastructure, fuel and transport taxes and subsidies, populace wealth, and city cultural and economic history. There are many others besides, and some researchers have reanalysed Newman and Kenworthy's original data with a re-emphasis on the explanatory power of these other variables (Gordon and Richardson, 1989; Kirwan, 1992).

Figure 1 shows the metro-area density and public transport energy efficiency of most of the same Australian and U.S. cities analysed in Newman and Kenworthy (1989), using the more recent dataset in Kenworthy and Laube (2001). While one can argue that this data indicates a negative link between city density and public transport energy use $^{2}$, there is still significant city and country specific variation unexplainable by macro scale density. While other factors such as those already mentioned likely explain part of this variation, it is highly likely that some significant portion of the unexplained variation is related to urban spatial structure, but at spatial scales below that of the city as a whole - neighbourhood, suburban, and city-subregion. The following analysis attempts to determine the relationship between travel behaviour and urban structure in Australian cities, by examining modal split for the journey to

\footnotetext{
${ }^{2}$ Although not shown in the figure, the least squares fit to the Australian and U.S. cities shown (both collectively and separately) are all negative.
} 


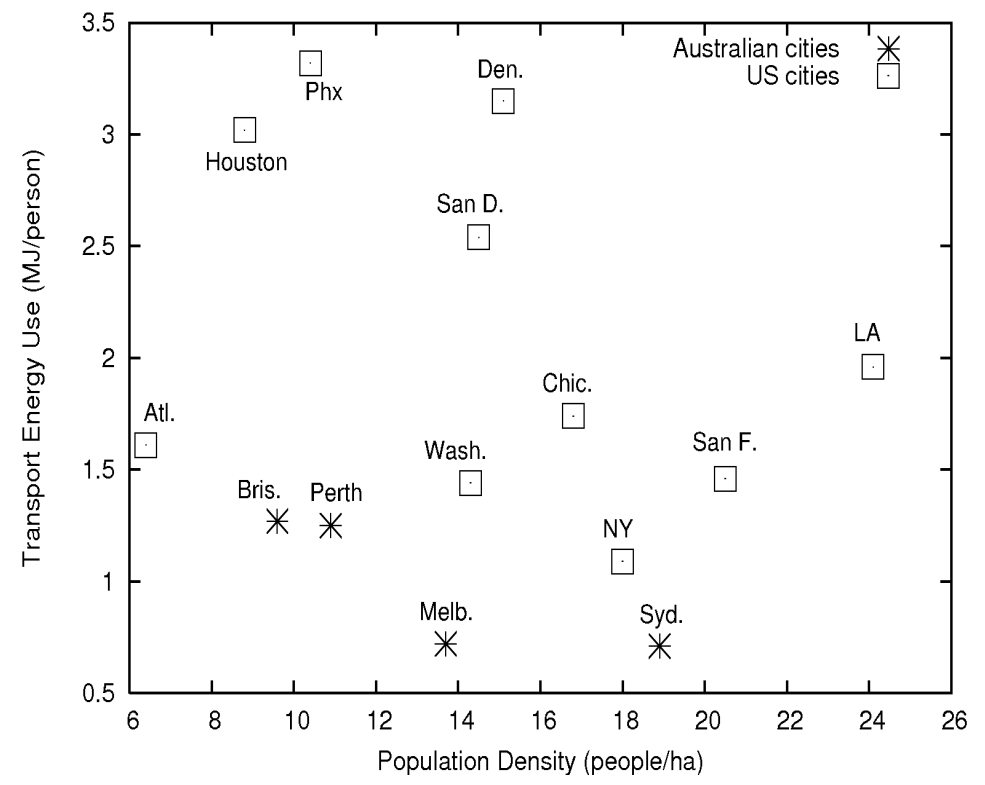

Figure 1: Total transport energy for Australian and U.S. cities of varying densities (in order of increasing density: Atlanta, Houston, Brisbane, Phoenix, Perth, Melbourne, Washington, San Diego, Denver, Chicago, New York, Sydney, San Francisco, Los Angeles). Source: Kenworthy and Laube (2001).

work.

\section{Data}

For our initial analysis, we use the Australian Bureau of Statistics 2001 Census data, at the Collection District level, which is the smallest area over which data is aggregated - generally comprising of around 500-1000 persons in an urban area. This can result in spatial aggregation over areas as little as $2500 \mathrm{~m}^{2}$, though $250000 \mathrm{~m}^{2}$ is more typical. Individual unit record data is available, but without valuable spatial information, and so is not useful for spatial analysis. The ABS census data, while having the disadvantage (over travel survey data) of being spatially aggregated, does have the advantage that it has comprehensive spatial coverage, is collected at (for all practical purposes) a single point in time, and has a uniform survey/collection methodology across Australia's urban areas.

The distinct advantages of the census data make it useful as an alternative to more typical travel survey/diary methods. Travel survey methods collect richer, more detailed information about travel patterns and preferences at the household level, but suffer from problems of their own. The expense of collection means that only a very small subset of all households can be surveyed, and so the samples are usually spread thinly over a wide geographic area. Household travel behaviour is also known to be highly variable (even after controlling for important demographic variables). There are a few different 
approaches that can be taken in response to the high variability in individual travel behaviour, which we will not describe in detail here, except to say that one common approach is to aggregate both spatially and temporally to reduce variance ${ }^{3}$. Such an approach is troubling, as it is the first rule of urban economics and geography that location matters, and, given the spatial aggregation necessitated by survey size, it seems unlikely that all relevant spatial information is captured by transport surveys and models. While using Census data allows us to work at a finer spatial scale, with more reliable data, the drawback is that we are limited to working with the journey to work as the only description of actual travel behaviour ${ }^{4}$. Though origin-destination journey to work trip data is available from the ABS, obtaining it at the Collection District level for each mainland capital is expensive, and requires significant additional processing and analysis. In this paper, we analyse only modal choice by origin, as this simplification allows us to easily compare modal choice patterns across the mainland Australian capitals ${ }^{5}$. We do this only as a first step: In other ongoing research, we are analysing origin-destination data.

For each of the mainland state capitals, we define a broad latitude/longitude bounding box that includes the metropolitan area of the city. The top-left and bottom-right corners of the bounding boxes are shown for each city in Table 1. Every Collection District that has a centroid within the bounding box and a population density greater than 5 people per hectare ${ }^{6}$ is defined as part of the residential urban area of that city.

\begin{tabular}{|c|c|c|}
\hline City & Top-left Lat/Long & Bottom-right Lat/Long \\
\hline Sydney & $-33.4 / 150.7$ & $-34.25 / 151.5$ \\
Melbourne & $-37.55 / 144.25$ & $-38.5 / 145.6$ \\
Brisbane & $-27.28 / 152.95$ & $-27.7 / 153.4$ \\
Perth & $-31.65 / 115.6$ & $-32.6 / 116.05$ \\
Adelaide & $-34.66 / 138.45$ & $-35.2 / 138.75$ \\
\hline
\end{tabular}

Table 1: Bounding boxes that include the bulk of the metropolitan areas of the mainland Australian state capitals.

This definition of residential urban area has the advantage that it avoids the need to deal with artificial boundaries, which can introduce significant distortions to measures of urban form, such as density ${ }^{7}$. We do not use the well known definition of urban centre provided by the Australian Bureau of

\footnotetext{
${ }^{3}$ Corpuz et al. (2006) aggregated 9 years worth of data at the Travel Zone level. There are approximately 7 Collection Districts to each Travel Zone in Sydney, on average. Hensher and Ton (2002) aggregated at the ABS Statistical Sub-Division level in their analysis of mode choice.

${ }^{4}$ Car ownership provides important indirect evidence, but we do not discuss this here, except as it relates to commute mode choice.

${ }^{5}$ While we do include Adelaide in our analysis, it does not receive the same attention as the other 4 state capitals, as it rained in Adelaide on the morning of the 2001 Census, and rain is known to affect mode choice.

${ }^{6}$ After trial and error, we found this cutoff value the most effective in excluding urban-fringe agriculture and hobby-farmers while still including what we would consider genuinely urban development.

${ }^{7}$ It avoids, for example, the inclusion of large areas of land that are within city boundaries, but which are not developed.
} 


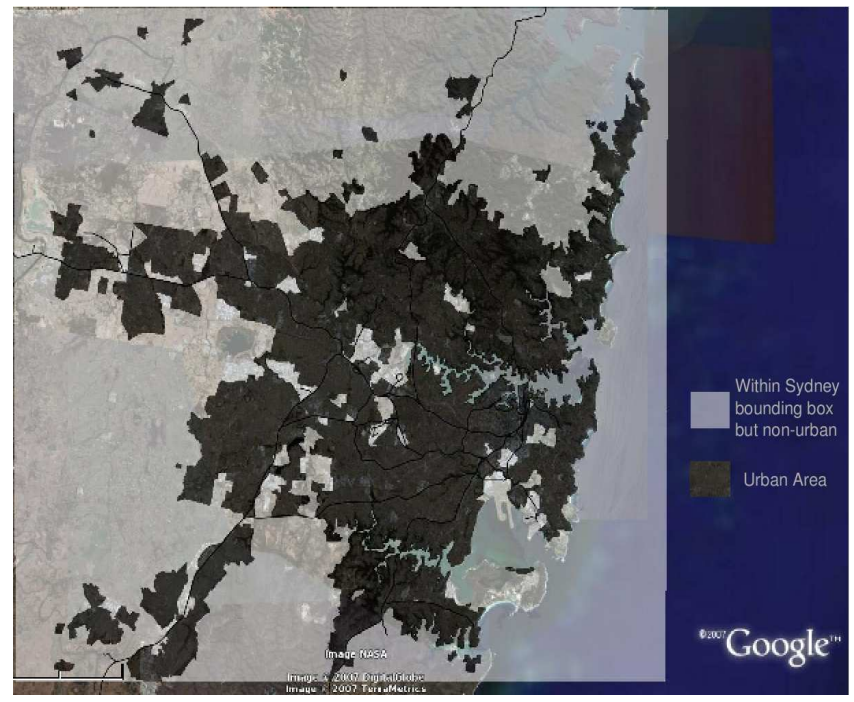

Figure 2: The areas of the Sydney basin defined as urban residential by our method.

Statistics (see Australian Bureau of Statistics (2005)), as the combination of the low population density threshold used ( 2 people/ha), and the general criteria for inclusion, can result in large areas of sparsely inhabited land being included. In other analyses, the ABS definition may be more appropriate, but because we use population density extensively in this paper, and because our indicator variable (public transport mode share) only makes sense in residential areas, our criteria for inclusion is more appropriate for this analysis. Our approach, because it excludes even inner city areas with low population densities (such as parkland and industrial land), results in a higher metropolitan-area density ${ }^{8}$ than other studies, but the general inter-city ranking is comparable with other estimates of macro-scale density (see Figure 3), allaying concerns that our unusual definition of an urban area produces results so radically different from traditional definitions that it will distort the analysis.

\section{Analysis and Results}

Let us consider two hypothetical cities. Suppose these cities have the same size and population (and hence the same aggregate population density). These cities may, nonetheless, have significantly different distributions of urban population. One might be a traditional mono-centric city with population densities declining monotonically beyond an inner city employment core. The other might be poly-centric. The possibilities are of course endless. Making fairly strong assumptions about the validity of the classic urban economic model of Alonso (1964); Mills (1967); Muth (1969), one can argue, as Bertaud and Malpezzi (2003) do, that economic forces will dictate a more or less Muthian inverse exponential

${ }^{8}$ Calculated in our study as the sum of urban Collection District populations over the total area covered by those Collection Districts. 


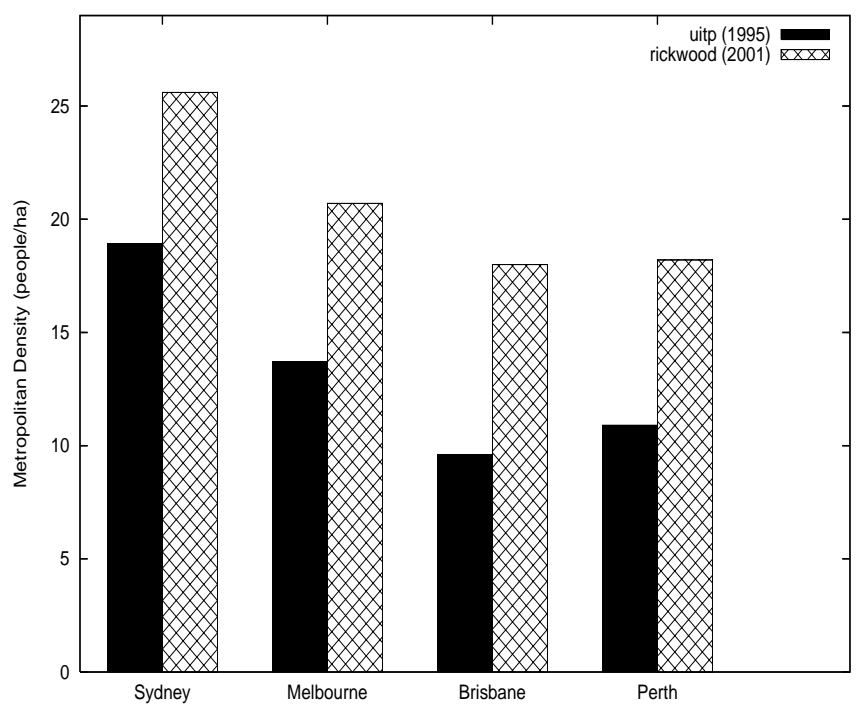

Figure 3: Metropolitan population density calculated 'top-down' from Kenworthy and Laube (2001) (with key uitp) in 1995, against metropolitan density calculated 'bottom-up' from Collection District data (with key cd) in 2001.

population density gradient, provided there is a reasonably free land market. However, the limitations of the theory, land market restrictions, and geographic constraints can all make actual observed patterns distinctly non-Muthian. Without knowledge of the finer scale structure of the cities, our ability to make sense of city-level outcomes is limited.

If our interest is in urban travel mode (private auto versus public), we can reasonably suppose that a city with a population distribution that allows for an efficient public transport system will have more efficient public transport outcomes. It is generally acknowledged that higher density development is more suitable for public transport. The actual argument is straightforward - the scale economies of mass transit are obvious, but require land use clustered around transit stops, to allow for higher patronage (transit catchment area) and better overall transit network coverage (see Small (1992) for a lengthier exposition).

If we restrict ourselves to consideration of commute travel, we can use the ABS census data described in section 3 to analyse how micro-scale density measures are related to commute mode choice in modern Australian cities. Modern transport modelling treats mode choice within a discrete choice framework (McFadden and Train, 2000; Koppelman and Bhat, 2006) where mode share is determined by the relative utilities of the different modes, but such an approach requires extensive data collection. For examples of Australian work in this vein, see Hensher and Ton (2002); Hensher and Rose (2007). As an alternative to the standard discrete choice model approach, we contend that data aggregated at a fine spatial scale is sufficient to provide some useful descriptive statistics, and insights into likely individual behaviour. Figures 4a-d show the relationship between $C D$ level population density and public transport 


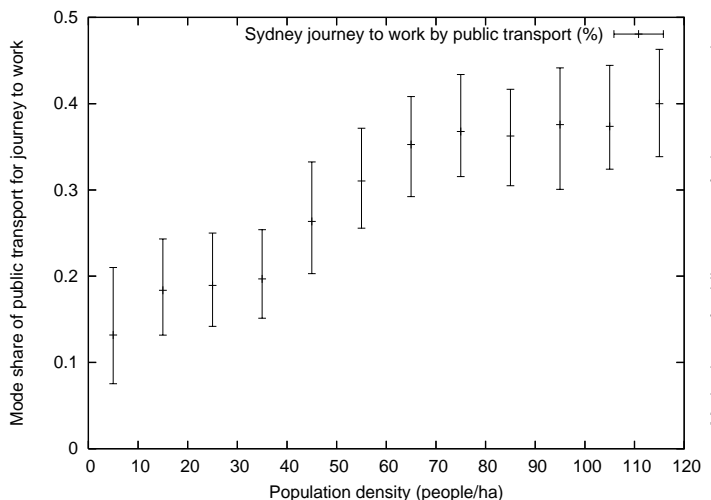

(a) Sydney

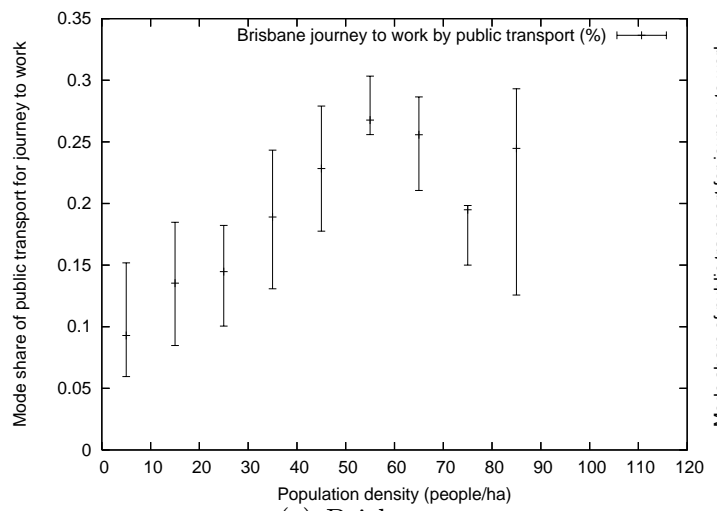

(c) Brisbane

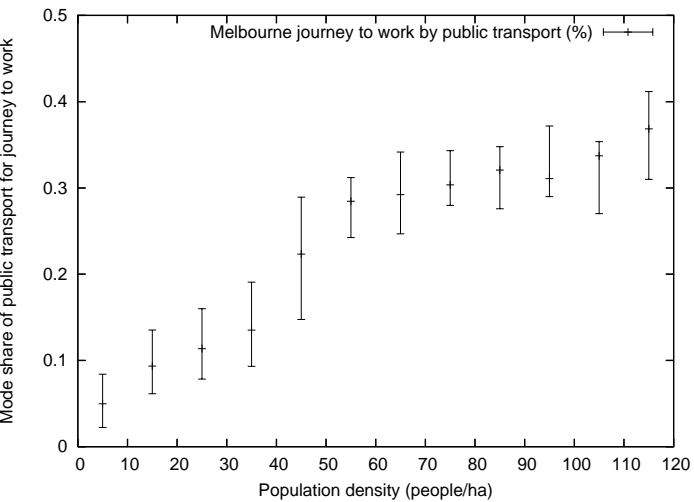

(b) Melbourne

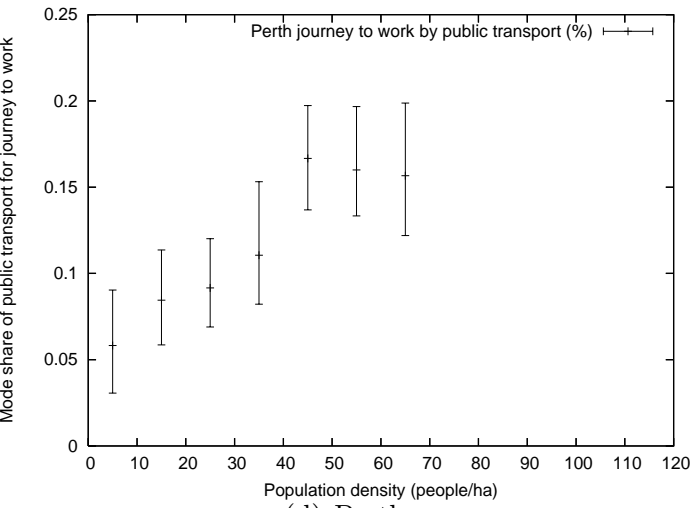

(d) Perth

Figure 4: Mode share of public transport for journey to work by origin CD density. CDs are grouped into 10 people/ha ranges, and the median and upper/lower quartiles are shown for each group.

commute mode share. Each figure shows the median and upper/lower quartiles of commute mode share for CDs within each 10 people/ha range, produced by grouping CDs into 10 people/ha ranges based on population density, sorting within each group by public transport commute mode share, and then calculating the median and upper/lower quartiles for each group. In Brisbane and Perth, higher density ranges contain few CDs, and so estimates are unreliable, as indicated by the irregular interquartile ranges.

Figures 4a-d are interesting, and, naively, one might suppose that they provide support for those arguing that higher-density living results in higher transport mode share. The pattern of increasing mode share with density up to around $70-80$ people/ha is consistent across the cities studied, so is unlikely a chance occurrence, but whether or not density is actually a determining factor, or simply masks some other underlying processes, is still far from clear. It is quite easy, for example, to mount an argument along land-economic lines that explains the patterns shown in Figures 4a-d. One need only point out that land prices increase closer to the city centre, which encourages substitution of capital for land (i.e. higher density), and hence it is simply proximity to the CBD that is the actual factor 


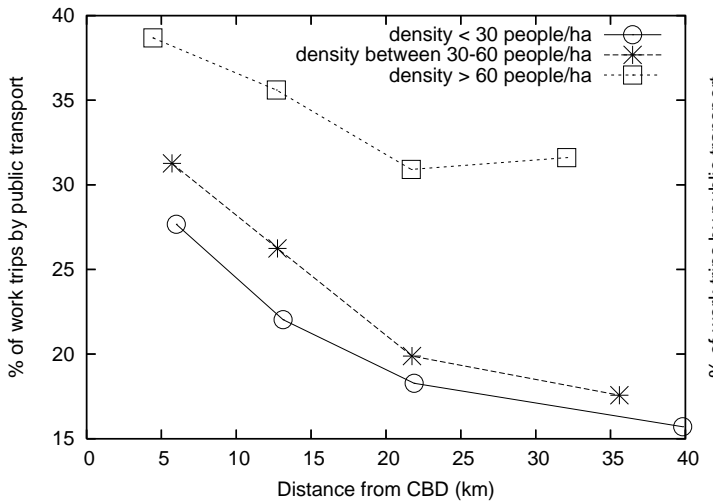

(a) Sydney

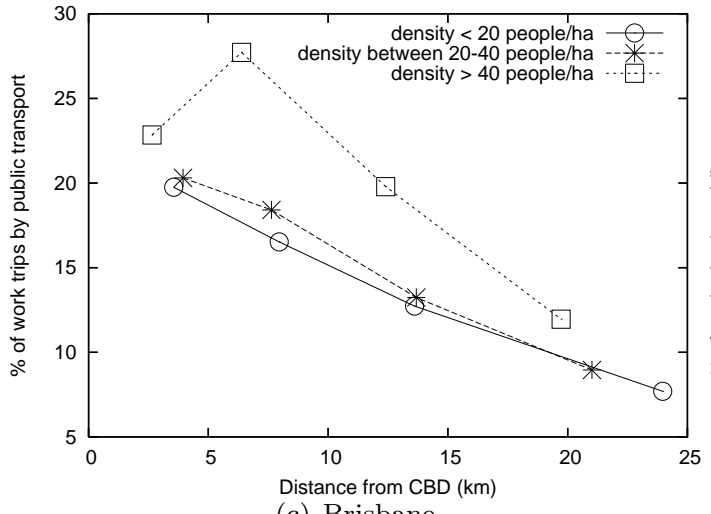

(c) Brisbane

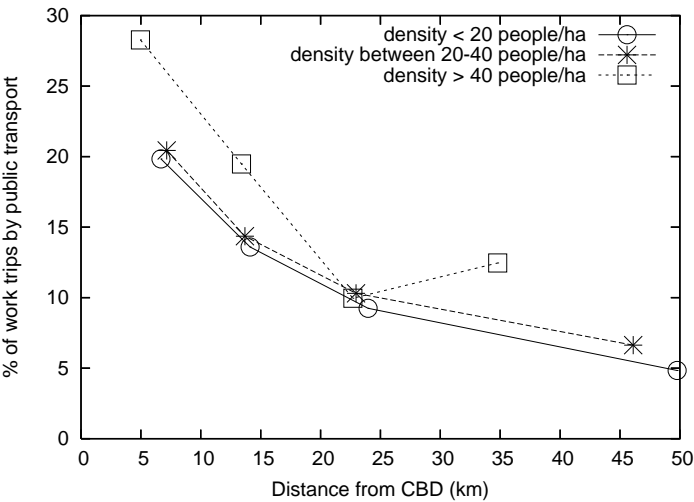

(b) Melbourne

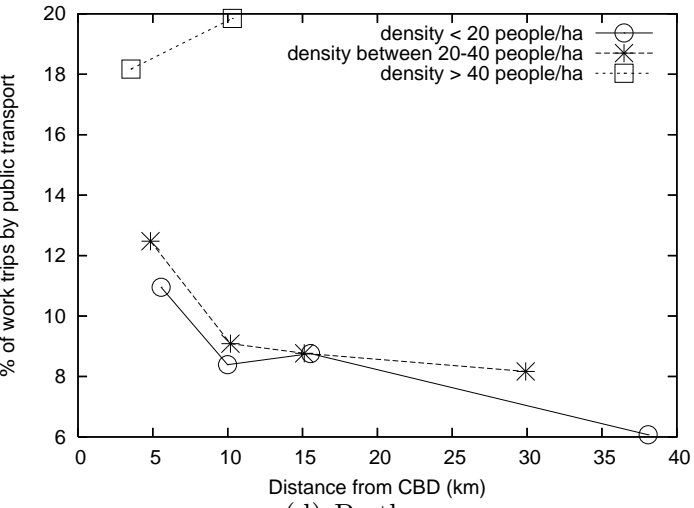

(d) Perth

Figure 5: Relationship between distance from CBD, residential density, and mode share of public transport for the journey to work.

influencing public transport mode share, and that the correlation with density is a by-product of urban economic forces. It is possible to test such an argument with the ABS data we have available. Figure 5 shows public transport mode share as a function of both density and distance from the CBD. We can see that public transport mode share does indeed decline with distance from the CBD, but that it also increases with density independently of distance from CBD. However, the difference between low and medium densities is small, with the largest increase in mode share being at higher densities.

While figures 5a-d suggest more strongly that density is an indicator of public transport use (and presumably provision), the effects seem limited at densities below 40 people/ha. There are large increases in public transport mode share at densities above 40 people/ha, independent of distance from CBD, and this might be taken as supporting evidence for some 'critical threshold' density of around 30-40 people/ha (as suggested, for example, by Newman and Kenworthy (1989); Holtzclaw (1994)), below which public transport fails to attract sufficient riders to support frequent reliable services. However, since it is quite clear that demographic factors vary with density, it is possible that demographic factors could at least partly explain the large increase in public transport ridership in high-density areas. A separate demographic analysis confirms that low and medium density areas are 


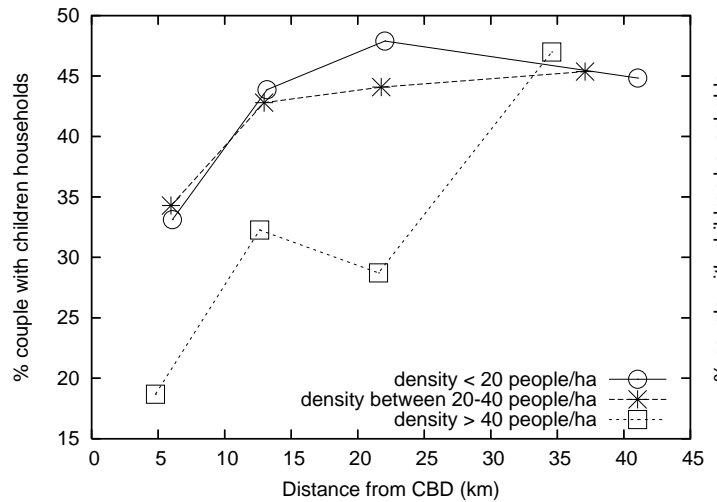

(a) Sydney

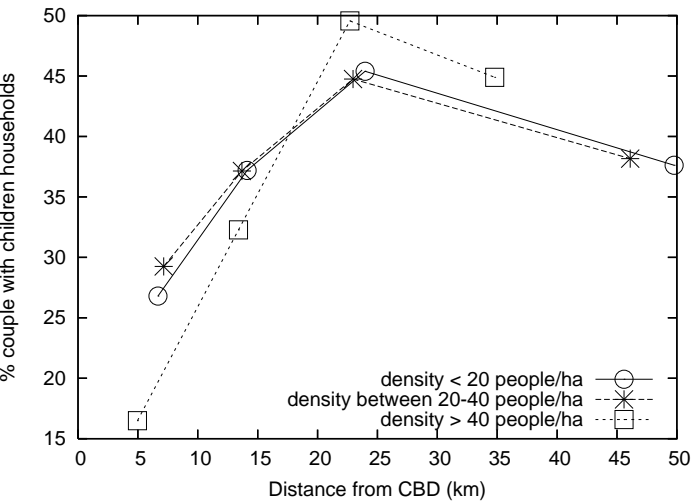

(b) Melbourne

Figure 6: Shows varying demographics with distance from the CBD and micro-scale urban density.

(roughly) demographically comparable, but this is not the case for high density areas. Full details of the demographic analysis are not be presented here, due to space limitations, but, for an illustration, see Figure 6, which shows the variation (with distance and density) in the proportion of households that consist of a couple with dependent children in Sydney and Melbourne. The same analysis also shows that some 'obvious' relationships hold: personal income decreases with increased dwelling density (independently of distance from $\mathrm{CBD}$ ); personal income decreases with increased distance from the $\mathrm{CBD}$; inner-ring residents are more likely to be professionals without children; inner-ring residents are more likely to rent. This agrees with other Australian work documenting that it is families who cannot afford detached housing, and affluent professionals seeking an urban lifestyle, that are likely to live in higher density areas (Reynolds and Porter, 1998; Vipond et al., 1998; Yates, 2001; Bunker et al., 2005).

Since inner-ring residents are distinct from middle and outer-ring residents, and since, in cities other than Sydney, almost all high density development is in the inner-ring, it is difficult to tease apart demographic and income effects from location and spatial structure effects. Our approach is to run two regressions: the first on Collection District data from all capitals; and the second on Collection Districts in Sydney alone, which has sufficient demographic and spatial diversity at all densities to allow for a controlled analysis. If results in Sydney are different from those for all state capitals, we should be wary of the all-capitals results. In addition, the Sydney-alone analysis serves as a base case for a more detailed Sydney-specific analysis, which we describe later. Initially including demographic variables (such as household income, proportion of households being families with children, etc.), we found significant collinearity between variables, and found that income and the proportion of households being families with children were themselves good predictors of car ownership (see Table 3). We chose to exclude family structure and income, and retain cars per household as an independent variable because household structure and income are generally accepted as major causal factors determining car 
ownership, a claim further strengthened by the regression results shown in Table 3. Indeed, this is why, in disaggregate discrete choice modelling with a nested logit model, mode choice is often conditioned on car ownership.

The results of the two regressions for journey to work mode split are shown in Table 2. In both cases, the same predictor variables were chosen. The results suggest that, in Australian cities generally, and in Sydney, that distance from the CBD, city-wide factors, and car ownership (which is itself determined by demographic factors), are important, but that local-area density seems to have a small direct effect. However, local area density also has an indirect effect, as it is associated with reduced car ownership a major determinant of modal choice. Results based on data from Sydney alone (which has a higher proportion of higher density development), are not greatly different from results on all capital cities. For an analysis of mode choice using a small number of aggregate variables, the explanation of variance is surprisingly good, and the consistency of the results suggests that local area density is, if not a causal factor, at least a useful proxy for predicting car ownership and mode choice. A more important factor, however, seems to be the general spatial structure of the city (measured in our regression, we would argue, by city-specific dummy variables), and location within the city.

\begin{tabular}{|c|c|c|}
\hline Variable & All cities & Sydney \\
\hline constant & 0.912 & 0.55 \\
distCBD & $0.004(0.333)$ & $0.005(0.354)$ \\
localpopden & $-0.021(-0.081)$ & $-0.008(-0.035)$ \\
carsperhh & $0.247(0.521)$ & $0.281(0.647)$ \\
sydney-dummy & $-0.195(-0.539)$ & $\mathrm{NA}$ \\
melb-dummy & $-0.101(-0.278)$ & $\mathrm{NA}$ \\
brisbane-dummy & $-0.084(-0.153)$ & $\mathrm{NA}$ \\
perth-dummy & $-0.044(-0.087)$ & $\mathrm{NA}$ \\
$r^{2}$ & 0.746 & 0.753 \\
\hline
\end{tabular}

Table 2: Regression results for Australian capitals generally (left column) and Sydney specifically (right column) for mode share of automobile (dependent variable, arcsine-root transformed). Standardized coefficients in parentheses. All variables significant at $p=0.001$ level.

Our results are understandable if one considers that, within a given city, local area density serves as a useful proxy for relative local access to a transit stop, and a measure such as 'distance from CBD' acts as a reasonable proxy for the overall accessibility (to destinations) provided by a local transit stop. To substantiate these claims, we undertake a more detailed analysis of mode choice in Sydney, using more sophisticated land-use and transport variables, rather than the coarse proxies we have used so far.

\subsection{Sydney Specific Analysis}

To investigate further our intuition that local area density and distance from the CBD serve as useful proxies for access to public transport, we make use of several detailed datasets of transport and land-use 


\begin{tabular}{|c|c|}
\hline Variable & All cities \\
\hline constant & 1.4924 \\
distCBD & 0.003 \\
localpopden & -0.0971 \\
income & 0.4097 \\
propcouplewkids & 1.3572 \\
sydney-dummy & -0.29 \\
melb-dummy & -0.0764 \\
brisbane-dummy & -0.0852 \\
perth-dummy & 0.0345 \\
$r^{2}$ & 0.846 \\
\hline
\end{tabular}

Table 3: Regression results for car ownership (dependent - cars per household) in the mainland Australian capitals. Standardized coefficients in parentheses. All variables significant at $p=0.001$ level.

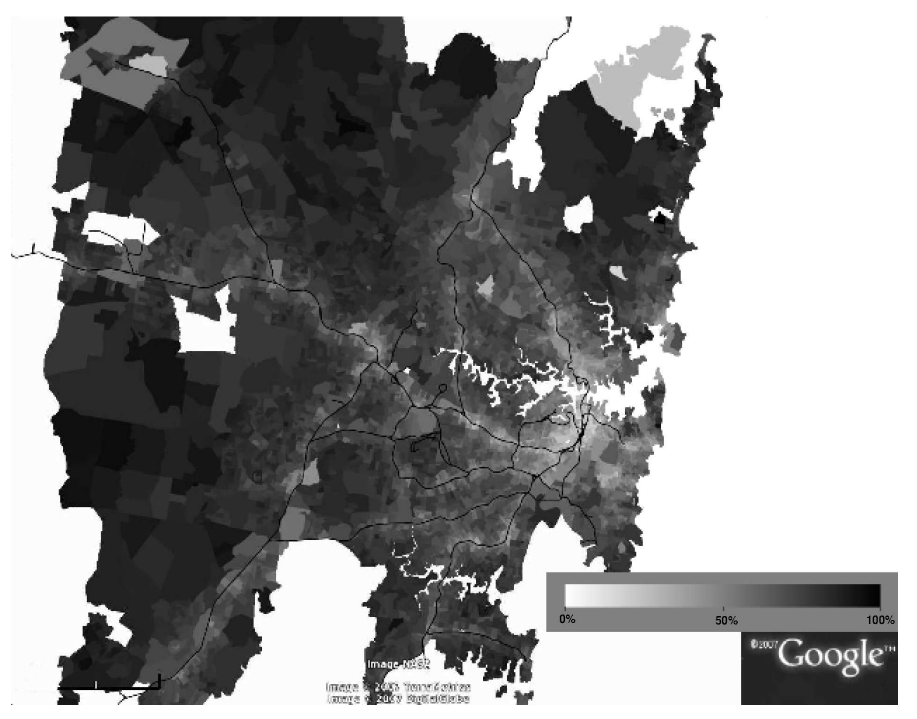

Figure 7: Proportion of journey to work trips made in a car in Sydney, at the ABS Census District level. Darker colours indicate higher proportions of trips by car (see embedded scale). Data Source: ABS 2001 Census.

characteristics in Sydney. Glazebrook (2002) developed detailed public and private transport accessibility measures for Sydney, at the Travel Zone level, of which there are around 800 in the Sydney basin (depending on how exactly one defines the extent of the basin). We have obtained access to this data, and include his accessibility measures in our analysis. We have also obtained, and include, the same land-use mix, employment, and transit access measures used by Corpuz et al. (2006) in their analysis of household vehicle use. Finally, we calculate and include our own measures of proximity to commercial land and walking-catchment proximity to jobs. Space limitations prevent the in-depth specification of how each measure is calculated, so we only provide more detailed descriptions for those variables that are found to be significant in the analysis that follows. 


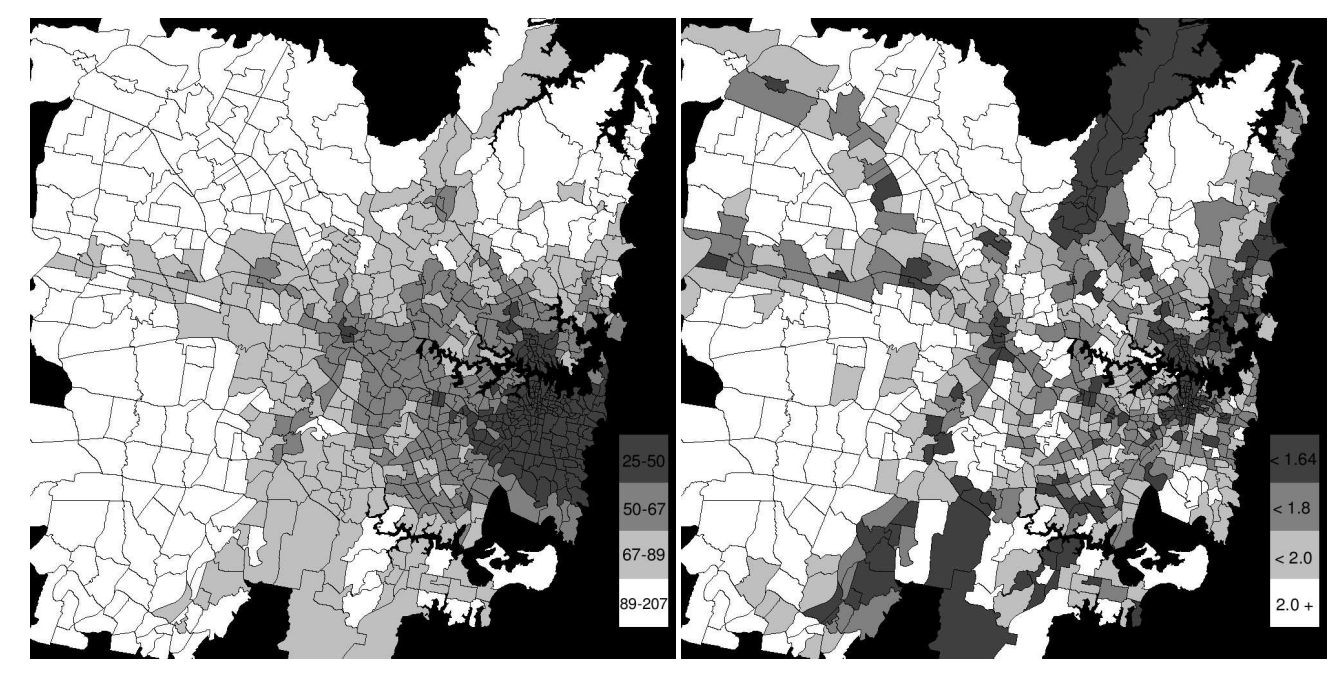

(a) Accessibility provided by transit

(b) Public/Private transport accessibility ratio

Figure 8: Left: Accessibility by public transport in Sydney. Right: Accessibility by public transport relative to accessibility provided by car. Source: Glazebrook (2002) .

Glazebrook (2002) describes the development of separate accessibility measures for public transport and private automobile in Sydney, at the Travel Zone level. The measure is a complex distance weighted measure of accessibility to all destinations, from all destinations. We include the separate measures themselves, as well as their ratio (reflecting the relative accessibility provided by public transport compared to car). Figure 8a shows public transport accessibility (darker colours indicate better access), and Figure $8 \mathrm{~b}$ shows the ratio of public/private accessibility (with darker colours representing relatively more competitive public transport).

To capture local area employment density, we use ABS journey to work data to calculate the number of jobs in each Travel Zone. Assuming jobs are uniformly distributed within Travel Zones ${ }^{9}$, we then calculate the number of jobs within a $1.5 \mathrm{~km}$ walking catchment of each Travel Zone centroid. Concretely, we calculate the following for each Travel Zone:

$$
\ln \left(1+\int_{0}^{2 \pi} \int_{0}^{1.5} \operatorname{jobs}(r, \theta) \mathrm{d} r \mathrm{~d} \theta\right)
$$

with each Travel Zone centroid acting as the origin, $r$ being the distance (in $\mathrm{km}$ ) from the centroid, $\theta$ being the direction, and jobs $(r, \theta)$ being the number of jobs at polar coordinate $(r, \theta)$ from the Travel Zone centroid. We have found the log transformation necessary, as otherwise employment in the CBD so dominates the measure that very little about employment concentration in other areas is available.

Results of the regression are shown in table 4. The $r^{2}$ of the model shown is slightly lower than

\footnotetext{
${ }^{9}$ Of course this is not the case, but Travel Zones are generally smaller where job concentrations are large, so the distortion introduced is generally not large, and the measure is still of use, as indicated in the analysis.
} 


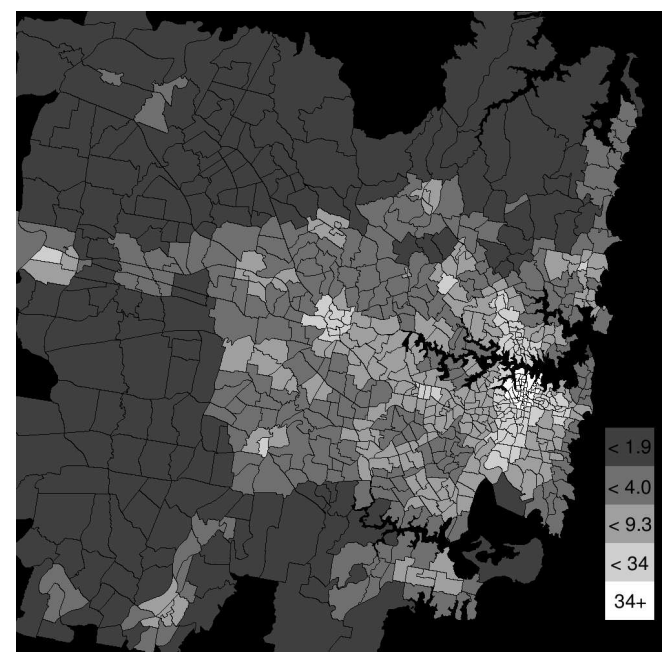

Figure 9: Measure of local area access to employment. Source: Authors' calculations based on ABS census data.

the best model obtained during analysis, but better models had problems with collinear variables. In particular, median household income improved model fit, but was, against expectations, negatively related to car commuting, and, as in the earlier analysis, positively related to car ownership. Somewhat surprisingly, other land-use and transport variables, such as the land-use mix and public transport access variables used by Corpuz et al. (2006), did not improve the model. Similarly, local area population density was not found to have a large effect ${ }^{10}$.

\begin{tabular}{|c|c|c|}
\hline Variable & Coefficient & Standardized Coefficient \\
\hline constant & 0.548 & NA \\
distCBD & 0.002 & 0.209 \\
carsperhh & 0.217 & 0.488 \\
PubPrivRatio & 0.06 & 0.104 \\
logLocalJobs & -0.045 & -0.254 \\
\hline$r^{2}$ & \multicolumn{2}{|c|}{0.873} \\
\hline
\end{tabular}

Table 4: Regression results for mode share of private automobile for the journey to work (dependent variable, arcsine-root transformed) in Sydney, at the Travel Zone level. All variables significant at $p=0.001$ level.

The regression results, again, are not surprising. As in the analysis with simpler explanatory variables, car ownership and increased distance from the CBD increase the likelihood of a car-based commute. The proportion of commuting by car also increased when local public transport provided access that was not competitive to that of the car (as measured by our PubPrivRatio variable - see Figure 8b). Also, as in our earlier analysis, we found that car ownership in Sydney was well explained $\left(r^{2}=0.899\right)$

\footnotetext{
${ }^{10} \mathrm{~A}$ small, but statistically significant effect for local area population density was detected in many of our regressions, but was, against expectations, positively related to car mode share, and also suffered from collinearity problems.
} 
by household characteristics (income and proportion of households with children), and coarse urban structure/location descriptors (local area density and distance from $\mathrm{CBD})^{11}$, but, as more complex measures of urban structure and location are introduced, the strength of the association with local area density and distance from the CBD either disappears (in the case of distance from CBD), or lessens considerably (in the case of local area density).

Correlations between our complex transport/land-use variables and the simpler proxies used in the earlier analysis are shown in Table 5. Correlations are as one would expect, with local area population density, local area employment, and measures of access to public transport all positively correlated with one another, and negatively correlated with car ownership, distance from the CBD, and use of car for the commute. From this, it is easy to see that when the more useful measures such as car ownership, local employment, and public transport access are unavailable, local area density can serve as a useful proxy, and this is why it so frequently shows up in the literature as being associated with a higher modal split for public transport. As one would expect, if one leaves car ownership out of the regression, local population density, local jobs, and distance from the CBD all have stronger effects, in line with most other research.

\begin{tabular}{|c|c|c|c|c|c|c|c|}
\hline & carsperhh & distCBD & PPRatio & localJobs & PopDen & ptaccess & carjtw \\
\hline carsperhh & 1 & 0.6 & 0.66 & -0.82 & -0.69 & -0.73 & 0.89 \\
distCBD & 0.6 & 1 & 0.47 & -0.68 & -0.61 & -0.69 & 0.72 \\
PPRatio & 0.66 & 0.47 & 1 & -0.61 & -0.59 & -0.65 & 0.68 \\
localJobs & -0.82 & -0.68 & -0.61 & 1 & 0.64 & 0.68 & -0.86 \\
localPopDen & -0.69 & -0.61 & -0.59 & 0.64 & 1 & 0.75 & -0.63 \\
ptaccess & -0.73 & -0.69 & -0.65 & 0.68 & 0.75 & 1 & -0.68 \\
carjtw & 0.89 & 0.72 & 0.68 & -0.86 & -0.63 & -0.68 & 1 \\
\hline
\end{tabular}

Table 5: Correlations between variables describing urban structure and location in Sydney. All correlations significantly different from 0 , at a 0.001 confidence level.

\section{Discussion}

On a purely descriptive front, the picture painted from our analysis of Australian cities is fairly clear. Within a city, there is a consistent increase in public transport mode share with increasing local density, independent of other factors. There is also a consistent reduction in public transport mode share with distance from the CBD, independent of other factors. The strength of these relationships lessen as more complex measures of urban form and access to public transport are introduced into the analysis, suggesting that local area density and distance from the CBD are useful proxies for transit-based accessibility. Having restricted ourselves, thus far, primarily to description and narrow analysis we now

\footnotetext{
${ }^{11}$ Full analysis omitted due to space limitations.
} 
allow ourselves a few more general comments, and a speculative one or two.

Between cities, public transport mode share is generally higher in cities with higher metropolitan density. We do not find these results surprising, but the weakness of local area density as a direct determinant of mode choice may surprise some. Our more detailed analysis of Sydney suggests that local area density is correlated with better access to public transport, and hence ceases to provide much explanatory power after more sophisticated measures of transit access are introduced. Even serving as a proxy, without complex land-use/transport measures, the effect of local area density is small relative to distance from the CBD and car ownership. However, the indirect link between local area density and car ownership increases its usefulness in situations where car ownership information is unavailable. Given our results, we do not find it surprising that other studies that include complex land use and transport variables find no (or small) effects of density (Boarnet and Crane, 2001; Crane and Crepeau, 1998). Similarly, it is unsurprising that studies relying heavily on density as a measure of urban structure (such as Newman and Kenworthy (2006)) find a strong link between density and transport outcomes such as car ownership, car use, or mode split.

The similarity of figures $4 a-d$, and the regression results for Sydney and the Australian mainland capitals suggest to us a simple formulation of the relationship between transit use and city structure, presented in Figure 10. Within a given city, we suggest that there is a function relating better access to local public transport and higher public transport use. However, this effect is relatively small, which explains the difficultly in detecting marginal effects of small scale improvements to local transit infrastructure (Boarnet and Crane, 2001; Crane and Crepeau, 1998). Access provided by local transit, on the other hand, is a much better predictor of transit use. Accessibility by public transport is also related to local access to a transport stop, but is more strongly related to general city wide factors, such as transport network structure and activity distribution. Concretely, we suggest that improved local access to transport moves one a small distance left or right along one of the dashed curves in Figure 10; moving to/from a major transit node moves one a long distance along the horizontal axis; and changes to overall metropolitan land use and transportation shifts the entire curve up or down. Vertical (citywide) factors clearly change more slowly than local factors. In this model, changes to travel behaviour as a result of improved local transit provision do not occur only at the local scale. A new rail line will increase public transport use along that rail line (a horizontal effect), but also, will result in increased patronage across the urban area because of the overall improvement in transit coverage (a vertical one). That this metropolitan scale effect will be small in any given area, makes its effect difficult to detect on anything but on a city-scale. Large scale inter-city comparisons consistently show a relationship between transit network kilometres and transit mode share (Badoe and Miller, 2000; Kenworthy and Laube, 1999). Under our formulation, one can classify urban planning measures as either horizontal 


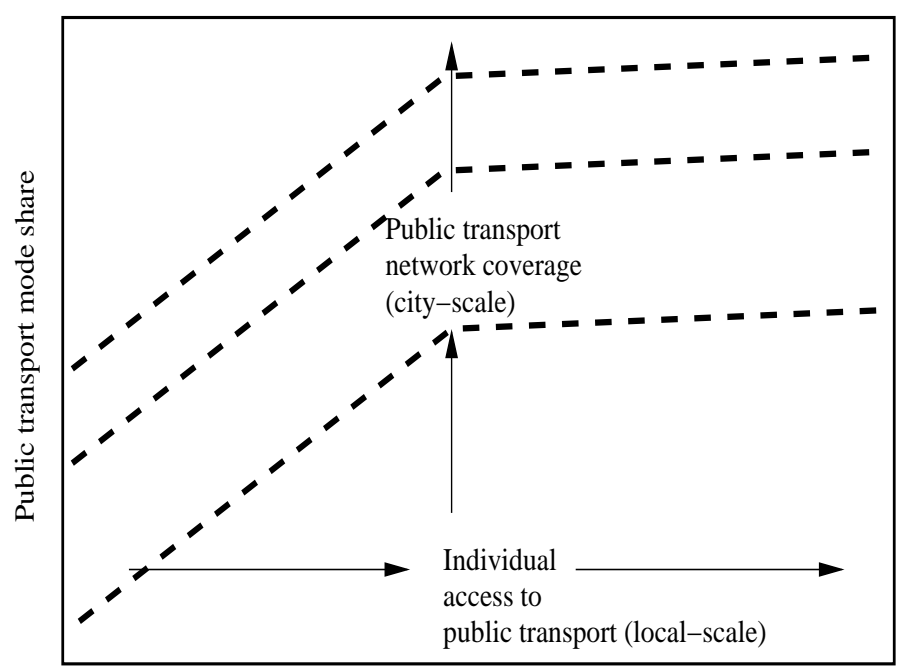

Local access to transit

Figure 10: Proposed model for the effect of micro and macro scale factors on public transport mode share, based on empirical results shown earlier in Figures 4a-d.

ones (i.e. affecting local land-use/access) or vertical (metropolitan land-use/access), as illustrated in Figure 11.

While many studies note that that self selection effects are important in transport studies, and difficult to control for (Levinson and Kumar, 1997; Cervero, 2002), the consistent patterns found in our inter-city analysis suggest that independent effects of urban structure are still significant, because while it is plausible that people select residential location based on transit availability, it seems less likely that people will select cities based on transit availability. Given that there is a uniform trend to higher transit mode share with increasing macro-scale density, it seems likely that self selection is only part of the explanation. This assessment fits with general inter-city review studies (Kenworthy and Laube, 1999; Bento et al., 2003; Baum-Snow and Kahn, 2005; Bento et al., 2003).

If our suggested model (Figure 10) is valid, and the simplifying assumptions inherent in our analysis are not too distorting, then they suggest that it is the vertical component that dominates, and that moderate increases in local area densities, without changes to transport infrastructure, will result in no change in transit use. Even the improved transit provision typically associated with increases in local area density will produce relatively modest increases in transit use, all other things equal. However, to consider these marginal effects alone is misleading, as systematically increasing local area densities allows not only for better provision of, and access to, transit at the local scale, but also for a more extensive overall public transport network in the longer term.

Our results indicate that planning strategies developed based on correlation analysis that indicates a link between local area density and transport behaviour are likely to disappoint those hoping for large 


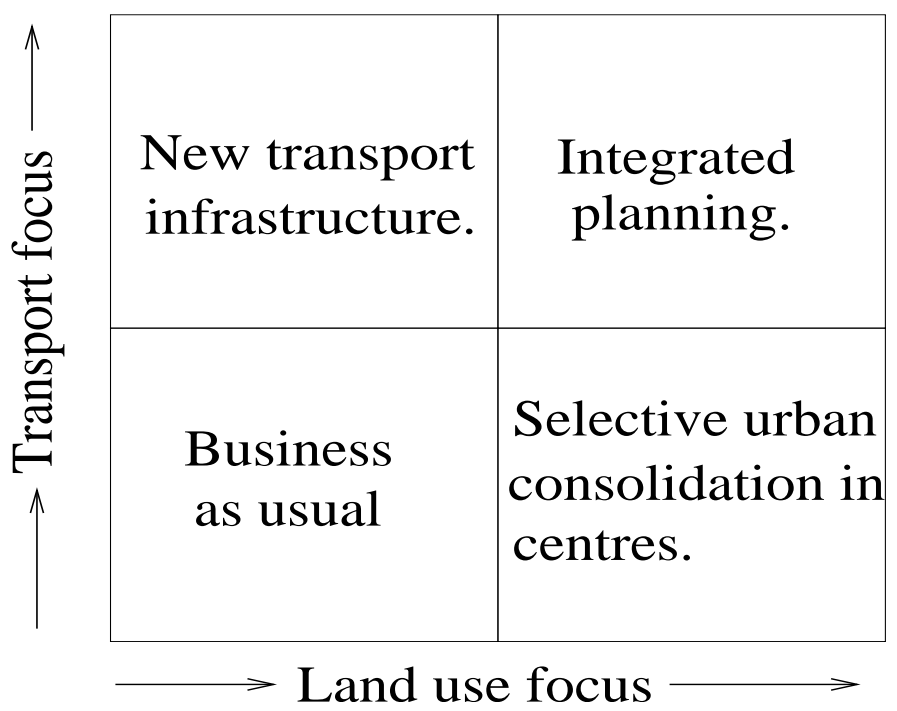

Figure 11: Classification of planning policies as horizontal (land-use) centric, or vertical (transport infrastructure centric).

short term increases in public transport use. In the short term, it is residential development in locations that are proximate to transit stops with good urban-area coverage that will have substantially higher mode share. This is hardly a surprising finding. For most Australian cities this implies residential development close to the CBD, which almost certainly means redevelopment at higher densities. However, significant development is still likely to take place on the urban fringe in Australian cities, and our analysis suggests that developing these areas at densities sufficient to allow for the efficient provision of transit will have a small to moderate short to medium term effect on car ownership and modal choice. We believe that it would be a mistake to conclude, however, that the type of residential development on the fringe is relatively unimportant in the longer term. To make such a conclusion is to ensure that the general access provided by the overall public transport network degrades over time, as the additional jobs and housing in new release areas become cut-off from the public transport network. Provision of jobs and housing within access to public transport, on the other hand, will result in increased mode share not just locally, but over the entire urban area.

The research detailed in this paper is an attempt at developing a deeper understanding of how urban structure relates to travel behaviour in Australian cities. Although we have restricted ourselves to mode share for the urban commute, we think it likely that some insights gained will prove relevant to non-work travel. Even limited insights are important, for many Australian cities are formulating or are in the early stages of implementing major strategic urban plans. Some are reaching capacity constraints in their transport networks while petrol prices are hitting record highs and a carbon tax is looking likely. In such an environment, the need for research that helps guide current and imminent 
planning initiatives has never been greater, as they will be steering our cities in directions that, if poorly chosen, seem likely to result in cities with poor environmental and economic outcomes.

\section{References}

Alonso, W. (1964). Location and Land Use. Harvard University Press, Cambridge, MA.

Australian Bureau of Statistics (2005). Australian standard geographical classification (ASGC). Catalogue Number 1216.0.

Badoe, D. A. and Miller, E. J. (2000). Transportation-land-use interaction: empirical findings in North America, and their implications for modeling. Transportation Research Part D, 5:235-263.

Baum-Snow, N. and Kahn, M. (2005). Effects of urban rail transit expansions: Evidence from sixteen cities, 1970-2000. Brookings-Wharton Papers on Urban Affairs, 1:147-206.

Bento, A. M., Cropper, M. L., Mobarak, A. M., and Vinha, K. (2003). The impact of urban spatial structure on travel demand in the United States. Technical Report 3007, World Bank.

Bertaud, A. and Malpezzi, S. (2003). The spatial distribution of population in 48 world cities: The role of markets, planning, and topography; and their implications for economies in transition. World Bank Report, World Bank, Washington DC.

Boarnet, M. and Crane, R. (2001). The influence of land use on travel behavior: specification and estimation strategies. Transportation Research Part A, 35:823-845.

Bunker, R., Holloway, D., and Randolph, B. (2005). The expansion of urban consolidation in Sydney: social impacts and implications. Australian Planner, 42(3):16-25.

Cervero, R. (1996). Mixed land-uses and commuting: Evidence from the American Housing Survey. Transportation Research Part A, 30(5):361-377.

Cervero, R. (2002). Built environments and mode choice: toward a normative framework. Transportation Research Part D, 7:265-284.

Cervero, R. and Duncan, M. (2006). Which reduces vehicle traffic more: Jobs-housing balance or retail-housing mixing? Journal of the American Planning Association, 72(4):475-490.

Cervero, R. and Kockelman, K. (1997). Travel demand and the 3d's: density, diversity, and design. Transportation Research Part D, 2:199-219. 
Corpuz, G., McCabe, M., and Ryszawa, K. (2006). The Development of a Sydney VKT Regression Model. 29th Australasian Transport Research Forum.

Crane, R. and Crepeau, R. (1998). Does neighborhood design influence travel? A behavioral analysis of travel diary and GIS data. Transportation Research Part D, 3:225-238.

Ewing, R., Cervero, R., Nelson, D., and Niles, J. (2001). Travel and the built environment: A synthesis. Transportation Research Record, 1780:87-114.

Frumkin, D. H., Frank, L. D., and Jackson, R. (2004). Urban Sprawl and Public Health: Designing, Planning, and Building for Healthy Communities. Island Press.

Geurs, K. T., van Wee, B., and Rietveld, P. (2006). Accessibility appraisal and integrated land-use transport strategies: methodology and case study for the Netherlands Randstad area. Environment and Planning $B, 33: 639-660$.

Glazebrook, G. (2002). Accessibility in Sydney: Patterns, Profiles, and Prospects. PhD thesis, University of Sydney, Sydney.

Golob, T. F. and Brownstone, D. (2005). The impact of residential density on vehicle usage and energy consumption. University of California Energy Institute Working Papers, Energy Policy and Economics 011.

Gordon, P. and Richardson, H. W. (1989). Gasoline consumption and cities - a reply. Journal of the American Planning Association, 55(3):342-345.

Hensher, D. and Rose, J. (2007). Development of commuter and non-commuter mode choice models for the assessment of new public transport infrastructure projects: A case study. Transportation Research Part A, 41(5):428-33.

Hensher, D. A. and Ton, T. (2002). Tresis: A transportation, land use and environmental strategy impact simulator for urban areas. Transportation, 29(4):439-457.

Holloway, D. and Bunker, R. (2005). Separating prospects from propaganda in urban consolidation. State of Australian Cities conference proceedings.

Holtzclaw, J. (1994). Using Residential Patterns and Transit to Decrease Auto Dependence and Costs. Natural Resources Defense Council.

Kenworthy, J. and Laube, F. (2001). UITP Millennium Cities Database for Sustainable Transport. 
Kenworthy, J. R. and Laube, F. B. (1999). Patterns of automobile dependence in cities: an international overview of key physical and economic dimensions and some implications for urban policy. Transportation Research Part A, 33:691-723.

Kirwan, R. J. (1992). Urban form, energy and transport: A note on the Newman-Kenworthy thesis. Urban Policy and Research, 10(1):6-22.

Koppelman, F. S. and Bhat, C. (2006). A Self-instructing Course in Mode Choice Modeling: Multinomial and Nested Logit Models. US Department of Transportation, Federal Transit Administration.

Levinson, D. M. and Kumar, A. (1997). Density and the journey to work. Growth and Change, 28:147-172.

McFadden, D. and Train, K. (2000). Mixed MNL models for discrete response. Journal of Applied Econometrics, 15(5):447-470.

Mills, E. S. (1967). An aggregative model of resource allocation in a metropolitan area. A.E.R. Papers and Proceedings, 57:197-210.

Muth, R. F. (1969). Cities and Housing: The Spatial Pattern of Urban Residential Land Use. University of Chicago Press, Chicago.

Newman, P. and Kenworthy, J. (1989). Cities and Automobile Dependence: An International Sourcebook. Aldershot, England.

Newman, P. and Kenworthy, J. (1999). Sustainability and Cities: Overcoming Automobile Dependence. Island Press, Washington, DC.

Newman, P. and Kenworthy, J. (2006). Urban design to reduce automobile dependence. Opolis, 2(1):35-52.

Reynolds, J. and Porter, L. (1998). Melbourne's inner city revival. Urban Policy and Research, 16(1):6368.

Rodriguez, D. A., Targa, F., and Aytur, S. A. (2006). Transport implications of urban containment policies: A study of the largest twenty-five US metropolitan areas. Urban Studies, 43(10):1879-1897.

Small, K. A. (1992). Urban Transportation Economics. Routledge.

Troy, P. (1996). The Perils of Urban Consolidation: A Discussion of Australian Housing and Urban Development Policies. Federation Press. 
Vipond, J., Castles, K., and Cardew, R. (1998). Revival in inner areas. Australian Planner, 35(4):215222.

Yates, J. (2001). The rhetoric and reality of housing choice: The role of urban consolidation. Urban Policy and Research, 19(4):491-527. 